\title{
Perinatal And Post-Partum Care From Early Pregnancy To Postpartum Period.
}

\author{
Dr.Shiv Kumar Yadav ${ }^{1 *}$, Dr.Rajesh Venkataraman ${ }^{2}$, Dr.Jeet Bahadur Moktan ${ }^{3}$, Dr.Yogendra Shrestha ${ }^{4}$, \\ Renukaradhya chitti ${ }^{5}$. \\ 1,3,4,5 Research Scholar, Department of Pharmacy Practice, Sri Adichunchanagiri College of Pharmacy, \\ Adichunchanagiri University, Mandya - 571448, Karnataka, India. \\ ${ }^{2}$ Rajesh Venkataraman Professor and Head, Department of Pharmacy Practice, Sri Adichunchanagiri College of \\ Pharmacy, Adichunchanagiri University, Mandya - 571448, Karnataka, India.
}

\author{
Corresponding Author: \\ Dr.Shiv Kumar Yadav*, \\ Research Scholar, \\ Dept. of Pharmacy Practice, \\ Sri Adichunchanagiri College of Pharamacy, \\ Adichunchanagiri University, \\ Email: yadavshiv1222@gmail.com, \\ Contact No. +917022080384
}

\begin{abstract}
:
Introduction: Despite the fact that just a few researchers have examined the prenatal and postpartum periods, the findings from those few studies suggest an increase in prevalence through out pregnancy and the first six months after delivery. Pregnancy is a pivotal period in a woman's life, as she experiences significant emotional, physical, hormonal, and social changes. Pregnancy and the first six months after delivery (perinatal phase) can be taxing, leading in sleep deprivation, relationship difficulties, and feelings of isolation.
\end{abstract}

Materials \& Methods: Quality of care, perinatal care, India, hospital, intrapartum care, implementation, and still birth for period were searched in the PubMed database using MeSH terms. A narrative summary of the goals and outcomes was completed.

Conclusions: This study compiles a list of all prenatal social needs interventions that have been described in the literature to date. The majority of therapies have been for IPV, according to the findings of this study, and interventions that combine counselling or ongoing support have the best likelihood of lowering social risk factors and improving clinical outcomes.

Keywords: Newborn care, pregnancy and postnatal care are all topics that need to be addressed. 


\section{Introduction:}

Despite the fact that just a few researchers have assessed the prenatal and postpartum periods, the findings from those few studies suggest an increase in prevalence throughout pregnancy and the first six months after delivery [1]. Pregnancy is a pivotal time in a woman's life, during which she goes through numerous emotional, physical, hormonal, and social changes [2]. Pregnancy and the first six months after delivery (perinatal phase) can be taxing, leading in sleep deprivation, relationship difficulties, and feelings of isolation. Health care practitioners are typically the primary source of mental health resources and assistance for women throughout the perinatal period [3].According to the National Survey on Drug Use and Health (NSDUH), 5\% of women have been diagnosed with substance use disorders within the previous year. The proportion was 12 percent [4]. Among women in their prime reproductive years (18 to 25 years). The whole family is affected by maternal and paternal depression. The impact of maternal depression on the early newborn will be the emphasis of this research, as well as the role of the primary care clinician in perinatal depression recognition. Perinatal depression is a type of significant or minor depression that occurs during pregnancy or within the first year after a child's birth [5] perinatal depression is rather prevalent. Perinatal depression affects $10 \%$ to $15 \%$ of new moms, according to studies. Depression in pregnancy must be recognised and addressed for the mother's and fetus's health [6]. Due to increased contact with health professionals and improved health care coverage, pregnancy may be an optimal time to recognise and treat depression [7]. Preterm births have been observed to be five times higher in women, as well as an increased risk of maternal and infant complications [8]. PPD affects up to $15 \%$ of women after giving birth and can have long-term consequences for both the mother and the child [9]. According to the World Health Organization, depression is the fourth leading cause of disability and a significant contributor to global disease burden. Younger people, women, and those with more education and wealth are more likely to utilise the internet to find health or medical information [10]. Prenatal and postpartum care for up to 24 months were included in perinatal case management. ECHS assisted two rural Georgia counties with health professional shortages in all areas [11]. Untreated prenatal depression has been shown to affect the physical, cognitive, and interpersonal functioning of women and their children [12]. Because the mother and her child are in grave psychological and social hazards [13] The public health issue of adolescent pregnancy is a serious one. The current study took use of the large, economically diverse, and demographically representative sample available to investigate the connection between race/ethnicity and self-reported low mood during late pregnancy and early postpartum [14]. The parents are given extensive information regarding the delivery plans. It is critical that the parents devise their own delivery strategy, which should include the prospect of a live birth. This could include fetal monitoring, which we usually don't recommend unless the parents agree to a surgical deliver [15]. Perinatal outcome is a key metric for obstetric treatment and health. One of the resolution's key goals is to 
reduce the number of neonates born with low birth weight by at least one-third between 2000 and 2010 [16]. Depression is a common problem that affects millions of people around the world during pregnancy and the early postpartum period [17]. Pregnancy is often portrayed as a happy and healthy time in a woman's life, but it can also be a time when she is more sensitive to mental health issues including depression and worry [18]. Untreated depression during pregnancy has been related to poor birth outcomes as well as long-term consequences for the mother, child, and family. Pregnant women who are depressed are more likely to gain weight slowly and indulge in dangerous activities like drinking and smoking [19]. The World Health Organization's reproductive health programme has made maternal mortality reduction its primary goal [20]. Mental health screening during pregnancy has been endorsed by the American College of Obstetricians and Gynecologists, the United States Preventive Services Task Force, and the American Academy of Pediatrics as a way to improve pregnancy outcomes such as preterm birth and low birth weight, as well as maternal-child health and wellness in the long run [21]. Women should normalize their BMI before attempting pregnancy, according to the American College of Obstetricians and Gynecologists [22]. According to the data, social determinants of health (SDoH) have a significant impact on health. The SDoH relates to how individuals are born, grow up, live, work, and age [23]. A woman living with HIV and her infant will receive comprehensive care that includes reproductive options counselling, high-risk prenatal care, modified labor and delivery management, and postpartum and baby care. Collaboration with professionals in high-risk pregnancy management and HIV care for mothers and babies is essential for HIV-positive women's prenatal and reproductive health care [24]. Because of physical, physiological, and psychological changes, pregnancy is a psychosomatic event that is both rewarding, joyful, and stressful. Caregivers must reconstruct their internal experience and accommodate their new parental chores, roles, and connections during the pregnancy [25]. Infant-related issues32, such as sleeping and crying problems, have been connected to depression in moms and fathers [26]. Transitioning to parenthood is a tough time of life that requires considerable changes on the part of future parents, as well as a higher risk of depression [27]. Special attempts to reduce neonatal and perinatal mortality due to pregnancy and its outcome began in Chicago in the early 1930s under the guidance of Dr. Julius Hess and Dr. Herman Bondsmen [28]. Women may benefit from a variety of therapies, such as counselling on healthy behaviors [29] A number of healthcare organizations have stressed the importance of adequate prenatal care as a predictor of improved perinatal outcomes [30]. Perinatal depression is thought to be harmful to children's health because it comes at a critical moment in brain development when infants are completely reliant on their primary caregivers for physical care, security, and emotional control [31]. There have been several attempts to develop ethical prenatal care principles, with an emphasis on eliminating preventable variables that contribute to maternal morbidity and mortality [32]. Maternal activities and experiences during the prenatal period can have a long-term 
impact on a child's health [33]. Low energy and/or interest in everyday activities, sleep issues or changes in appetite/weight, poor focus, feelings of worthlessness, guilt, and/or hopelessness, and suicide thoughts are all symptoms of depressive disorders. Five or more specific symptoms, one of which must be a sad mood or loss of interest, must be present for at least two weeks for a major depression diagnosis to be made [34]. The need of organizational transformation was underlined in both papers, particularly increased collaboration between community midwives and obstetricians [35]. Anxiety during pregnancy increases the chances of getting PPDS [36]. One structural innovation that has yet to be empirically confirmed but has the potential to improve prenatal care is prenatal care in a group setting. Pediatric [37] Group care was used with some success, both verified and anecdotal. Although nurses consider pregnancy to be a physical condition, it is also a vital and crucial social part of our life[38]. Group care was used with some success, both verified and anecdotal. Although nurses consider pregnancy to be a physical condition, it is also a vital and crucial social part of our life [39]. Alcohol, cigarettes, and other drugs during pregnancy have been related to placental abruption, intrauterine fetal death, low-birth-weight neonates, neonatal abstinence syndrome, and early labor and birth [40]. Alcohol, cigarettes, and other substances during pregnancy have been related to placental abruption, intrauterine fetal death, low-birthweight neonates, neonatal abstinence syndrome, and early labor and birth [41]. Both physical and mental health require proper nutrition. Depression has been linked to nutrient deficiencies in folate, vitamin B12, calcium, iron, selenium, zinc, and polyunsaturated fatty acids (PUFAs) [42]. Healthy child development has long been viewed as a necessary foundation for reducing health and socioeconomic inequities throughout one's life [43]. The length of a patient's stay in the hospital is decreasing, and the focus of care is shifting to the patient's natural environment [44]. While age categories (e.g., 15-44 years) can be defined, "women of childbearing age" or "women of reproductive age" must be defined as well [45]. ELS has been demonstrated to disrupt neurological, cognitive, and affective functions, with long-term consequences for the brain and behavior [46]. Perinatal depression (PeD) affects 3 to $6 \%$ of all women, according to studies [47]. Other studies have compared births in birth centers to those in hospitals [48] The National Birth Center Study and others are examples. Women who felt competent and happy in their duties as mothers had a secure attachment style, as well as sensitive and responsive caring behavior, which supported the infant's development and growth [49]. During pregnancy and early parenting, both parents are more sensitive to psychological distress and the emergence or relapse of psychiatric disorders, including depression [50] 


\section{MATERIALS AND METHODS}

\section{Data sources:}

Our search method was created with the help of a medical librarian and was based on previously published studies on therapies for social needs in health care settings. The search phrases were made up of key words from four categories: (1) pregnant or recently delivered women; (2) SDoH; (3) screening and interventions; and (4) outcomes. In the Supplementary Appendix, we go over our whole search technique. We searched six databases for English-language papers describing health-care-related interventions (PubMed, Embase, Cochrane, CINAHL, Scopus, and Web of Science). We conducted a second search to see if any new papers had been published since the review began. The time limit for the search was not set in stone.

\section{Study Selection:}

The selection of papers for the review was based on the following criteria: Quantitative and qualitative data about PPND published in peer-reviewed articles or books in English. Articles were eliminated by title, abstract, or full text for maternal depression and lack of connection to the topic. Unpublished dissertations and theses, case reports and series, and other non-peer-reviewed material were also disqualified.

\section{Data extraction:}

The purpose of this review was to look into and organize the international literature on the relationship between prenatal attachment and perinatal depression in order to explain and debate new findings while also providing clinically valuable information. Following the inclusion and exclusion criteria. In the majority of research, there was a negative correlation between prenatal depression and prenatal attachment, as well as prenatal attachment and postpartum depression. Other studies, particularly those including male samples and pregnant parents in high-risk pregnancies, have failed to achieve this, generating mixed results.

\section{DISCUSSION:}

The goal of this review was to investigate and organize the international literature on the link between prenatal attachment and perinatal depression, in order to explain and discuss new discoveries while also giving clinically useful information. 41 papers were included after they met the inclusion and exclusion criteria. Prenatal depression and prenatal attachment, as well as prenatal attachment and postpartum depression, were found to have a negative connection in the majority of studies. However, other research, 
notably among male samples and pregnant parents in high-risk pregnancies, failed to do so, yielding mixed results.

\section{Outcomes:}

[Neonates (newborns) and babies (0-2 years)] and childhood (2-15 years)] Preterm (37 gestational weeks); SGA (birth weight 2,500 g, or > 2 standard deviations below the mean); LGA (birth weight > 90th percentile for age and sex, or $>4000 \mathrm{~g}$, or $>2$ standard deviations above the mean); childhood weight and obesity (body mass index 95th percentile for age and sex); circumference of the head, chest, and abdomen; circumference of the head, chest, and abdomen; circumference of the head, chest, and (visceral, subcutaneous, and abdominal).

\section{CONCLUSION}

This study compiles a list of all social needs interventions in perinatal care that have been previously described in the literature. The majority of therapy have been for IPV, according to the findings of this study, and interventions that combine counselling or ongoing support have the best likelihood of lowering social risk factors and improving clinical outcomes. One of the rare interventions that takes into account social demands is IPV. A more thorough investigation is required, encompassing not only IPV but also other types of social need. While some therapies for social needs may be beneficial, we believe they fail to address the underlying socioeconomic factors that underpin many health disparities, including those in maternal and child health.

\section{REFERENCE}

1. Field T. Paternal prenatal, perinatal and postpartum depression: A narrative review. Journal of Anxiety \& Depression. Vol. 1, no.1, (2018), pp. 102.

2. Silva R, Jansen K, Souza L, Quevedo L, Barbosa L, Moraes I, Horta B, Pinheiro R. Fatores sociodemográficos de risco de depressão perinatal: um estudo populacional no sistema público de cuidados de saúde. Brazilian Journal of Psychiatry. Vol.34, no.2,(2012), pp.143-8.

3. Farewell CV, Jewell J, Walls J, Leiferman JA. A mixed-methods pilot study of perinatal risk and resilience during COVID-19. Journal of Primary Care \& Community Health.vol.11, no. 3,(2020)pp. 123-125.

4. Galvin SL, Ramage M, Leiner C, Sullivan MH, Fagan EB. A cohort comparison of differences between regional and buncombe county patients of a comprehensive perinatal substance use disorders program in western North Carolina. North Carolina medical journal.vol.81, no. 3 (2020),pp.157-65. 
5. Earls MF, Committee on Psychosocial Aspects of Child and Family Health. Incorporating recognition and management of perinatal and postpartum depression into pediatric practice. Pediatrics.vol.126, no.5 (2010)pp.1032-1035.

6. Jevitt, C., Zapata, L., Harrington, M., \& Berry, Screening for perinatal depression with limited psychiatric resources. Journal of the American Psychiatric Nurses Association,vol.11, no.6, (2006),pp. 359-363.

7. Jevitt CM. Obesity and socioeconomic disparities: rethinking causes and perinatal care. The Journal of perinatal \& neonatal nursing. Vol.33, no. 2, (2019,) pp.126-35.

8. Kennedy HP, Farrell T, Paden R, Hill S, Jolivet RR, Cooper BA, Schindler Rising S. A randomized clinical trial of group prenatal care in two military settings. Military medicine. Vol. 176, no.10,( 2011), pp.1169-77.

9. Glynn LM, Davis EP, Sandman CA. New insights into the role of perinatal HPA-axis dysregulation in postpartum depression. Neuropeptides.vol. 47, no. 6,( 2013), pp.363-70.

10. Young-Wolff KC, Gali K, Sarovar V, Rutledge GW, Prochaska JJ. Women's questions about perinatal cannabis use and health care providers' responses. Journal of Women's Health. Vol. 29, no.7,(2020), pp.919-26.

11. Mobley SC, Thomas SD, Sutherland DE, Hudgins J, Ange BL, Johnson MH. Maternal health literacy progression among rural perinatal women. Maternal and child health journal. Vol. 18, no. 8,(2014) pp.1881-92.

12. Flynn HA, O'mahen HA, Massey L, Marcus S. The impact of a brief obstetrics clinic-based intervention on treatment use for perinatal depression. Journal of Women's Health.vol.15, no.10,(2006) pp.1195-204.

13. Lena SM, Marko E, Nimrod C, Merritt L, Poirier G, Shein E. Birthing experience of adolescents at the Ottawa General Hospital Perinatal Centre. CMAJ: Canadian Medical Association Journal.vol.148, no.12, (1993) pp.2149.

14. Segre LS, O'Hara MW, Losch ME. Racelethnicity and perinatal depressed mood. Journal of Reproductive and Infant Psychology.vol.24, no.02,( 2006) pp.99-106.

15. Calhoun BD. Perinatal hospice: Compassionate and comprehensive care for families with lethal prenatal diagnosis. The Linacre Quarterly.vol.77, no.2( 2010) pp.147-56.

16. Hassan AA, Abubaker MS, Radi EA, Adam I. Education, prenatal care, and poor perinatal outcome in Khartoum, Sudan. International Journal of Gynecology \& Obstetrics.vol.105, no.1,(2009) pp.66-7.

17. Sefogah PE, Samba A, Mumuni K, Kudzi W. Prevalence and key predictors of perinatal depression among postpartum women in Ghana. International Journal of Gynecology \& Obstetrics.vol.149, no.2( 2020 )pp. 203-10. 
18. Katon JG, Lewis L, Hercinovic S, McNab A, Fortney J, Rose SM. Improving perinatal mental health care for women veterans: description of a quality improvement program. Maternal and child health journal. Vol. 21,no.8(2017) pp.1598-605.

19. Byatt N, Simas TA, Lundquist RS, Johnson JV, Ziedonis DM. Strategies for improving perinatal depression treatment in North American outpatient obstetric settings. Journal of Psychosomatic Obstetrics \& Gynecology. Vol.33, no.4(2012) pp.143-61.

20. Simbar M, Nahidi F, Ramezani Tehrani F, Akbarzadeh A. Educational needs assessment for men's participation in perinatal care. EMHJ-Eastern Mediterranean Health Journal. Vol.17, no.9, (2011) 689-pp.696.

21. Lomonaco-Haycraft KC, Hyer J, Tibbits B, Grote J, Stainback-Tracy K, Ulrickson C, Lieberman A, van Bekkum L, Hoffman MC. Integrated perinatal mental health care: a national model of perinatal primary care in vulnerable populations. Primary health care research \& development.vol. 45, no. 3( 2019)pp.20.

22. Jevitt CM. Obesity and socioeconomic disparities: rethinking causes and perinatal care. The Journal of perinatal \& neonatal nursing.vol.33,no. 2(2019) pp.126-35.

23. Reyes AM, Akanyirige PW, Wishart D, Dahdouh R, Young MR, Estrada A, Ward C, Cruz Alvarez C, Beestrum M, Simon MA. Interventions Addressing Social Needs in Perinatal Care: A Systematic Review. Health equity. Vol.5, no. 1(2021) pp.100-18.

24. Money D, Tulloch K, Boucoiran I, Caddy S, Yudin MH, Allen V, Bouchard C, Boucher M, Castillo E, Gottlieb H, Kennedy VL. Lignes directrices pour ce qui est des soins à offrir aux femmes enceintes qui vivent avec le VIH et des interventions visant à atténuer la transmission périnatale: Résumé directif. Journal of Obstetrics and Gynaecology Canada.vol.36, no.8( 2014) pp.735-51.

25. Rollè L, Giordano M, Santoniccolo F, Trombetta T. Prenatal attachment and perinatal depression: $a$ systematic review. International journal of environmental research and public health.vol.17, no.8,( 2020) pp.2644.

26. Burgess A. Fathers' roles in perinatal mental health: causes, interactions and effects. New Digest.vol.53, no.4( 2011) pp.24-9.

27. Nanzer N, Rossignol AS, Righetti-Veltema M, Knauer D, Manzano J, Espasa FP. Effects of a brief psychoanalytic intervention for perinatal depression. Archives of women's mental health.vol.15, no.4( 2012) pp.259-68.

28. Wallace HM. Status of infant and perinatal morbidity and mortality: a review of the literature. Public Health Reports.vol.93, no.4( 1978) pp.386. 
29. Abu-Ghanem S, Sheiner E, Sherf M, Wiznitzer A, Sergienko R, Shoham-Vardi I. Lack of prenatal care in a traditional community: trends and perinatal outcomes. Archives of gynecology and obstetrics.vol. 285, no.5( 2012) pp.1237-42.

30. Wilson-Mitchell K, Rummens JA. Perinatal outcomes of uninsured immigrant, refugee and migrant mothers and newborns living in Toronto, Canada. International journal of environmental research and public health.vol. 10, no. 6( 2013) pp.2198-213.

31. Junge C, Garthus-Niegel S, Slinning K, Polte C, Simonsen TB, Eberhard-Gran M. The impact of perinatal depression on children's social-emotional development: a longitudinal study. Maternal and Child Health Journal. Vol. 21, no. 3(2017), pp.607-15.

32. Scott KA, Britton L, McLemore MR. The ethics of perinatal care for black women: dismantling the structural racism in "mother blame" narratives. The Journal of perinatal \& neonatal nursing.vol. 33, no.2 (2019) pp.108-15.

33. Kortsmit K, Garfield C, Smith RA, Boulet S, Simon C, Pazol K, Kapaya M, Harrison L, Barfield W, Warner L. Paternal Involvement and Maternal Perinatal Behaviors: Pregnancy Risk Assessment Monitoring System, 2012-2015. Public Health Reports. Vol. 135, no.2(2020) pp.253-61.

34. Dagher RK, Bruckheim HE, Colpe LJ, Edwards E, White DB. Perinatal depression: Challenges and opportunities. Journal of Women's Health.vol. 30, no.2( 2021) pp.154-9.

35. Posthumus AG, Schölmerich VL, Waelput AJ, Vos AA, De Jong-Potjer LC, Bakker R, Bonsel GJ, Groenewegen P, Steegers EA, Denktaş S. Bridging between professionals in perinatal care: towards shared care in the Netherlands. Maternal and child health journal. Vol.17, no. 10,(2013) pp.1981-9.

36. King L, Feeley N, Gold I, Hayton B, Zelkowitz P. The healthy migrant effect and predictors of perinatal depression. Women and Birth. Vol. 32, no.3(2019) pp.341-50.

37. Neumann DC. Alternative therapies for perinatal care: a holistic approach to pregnancy. Vol. 47, no. 3, (2015).pp 98

38. Côté-Arsenault D, Hubbard LJ. Improving Perinatal Care Through Theory Application. MCN: The American Journal of Maternal/Child Nursing. Vol. 44, no.6(2019) pp.345-50.

39. Ronca AE, Abel RA, Alberts JR. Perinatal stimulation and adaptation of the neonate. Acta Paediatrica. Vol.85, no.3(1996),pp:8-15.

40. Goler NC, Armstrong MA, Osejo VM, Hung YY, Haimowitz M, Caughey AB. Early start: a costbeneficial perinatal substance abuse program. Obstetrics \& Gynecology.vol. 119, no. 1( 2012) pp.102-10.

41. Goler NC, Armstrong MA, Osejo VM, Hung YY, Haimowitz M, Caughey AB. Early start: a costbeneficial perinatal substance abuse program. Obstetrics \& Gynecology.vol.119,no.1( 2012) pp.10210. 
42. Leung BM, Giesbrecht GF, Letourneau N, Field CJ, Bell RC, Dewey D, APrON Study Team. Perinatal nutrition in maternal mental health and child development: Birth of a pregnancy cohort. Early human development.vol.93, no.1,( 2016)pp.:1-7.

43. Kingston D, Tough S, Whitfield H. Prenatal and postpartum maternal psychological distress and infant development: a systematic review. Child Psychiatry \& Human Development. Vol43, no. 5(2012) pp.683-714.

44. Beňová E, Boledovičová M. COmmUNITy CaRe IN peRINaTal peRIOD. Journal of Nursing, Social Studies, Public Health and Rehabilitation.vol.5, no.3,( 2014)pp. 162-7.

45. Misra DP, Grason H, Weisman C. An intersection of women's and perinatal health: the role of chronic conditions. Women's Health Issues. Vol.10, no.5,(2000) pp.256-67.

46. King L. The Link between Perinatal Depression and DNA Methylation of the Oxytocin Receptor Gene: A Study of Mothers and Their Children. McGill University (Canada); vol. 98, n0. 2(2017).pp. 77.

47. Martinez-Borba V, Suso-Ribera C, Osma J. The use of information and communication technologies in perinatal depression screening: A systematic review. Cyberpsychology, Behavior, and Social Networking. Vol. 21,no.12(2018) pp.741-52.

48. Jackson DJ, Lang JM, Swartz WH, Ganiats TG, Fullerton J, Ecker J, Nguyen U. Outcomes, safety, and resource utilization in a collaborative care birth center program compared with traditional physician-based perinatal care. American Journal of Public Health.vol.93, no. 6,( 2003)pp.999-1006.

49. Galvin SL, Ramage M, Leiner C, Sullivan MH, Fagan EB. A cohort comparison of differences between regional and buncombe county patients of a comprehensive perinatal substance use disorders program in western North Carolina. North Carolina medical journal.vol.81,no. 3( 2020) ,pp.157-65.

50. Bruno A, Celebre L, Mento C, Rizzo A, Silvestri MC, De Stefano R, Zoccali RA, Muscatello MR. When fathers begin to falter: a comprehensive review on paternal perinatal depression. International journal of environmental research and public health.vol.17, no.4( 2020) pp.1139. 